\title{
UDC 621.039.616 \\ NEUTRAL BEAM CURRENT RATIO IN THE NEUTRON SOURCE FNS-ST
}

\author{
E.D. Dlougach, A.A. Panasenkov, B.V. Kuteev, E.A. Filimonova
}

NRC «Kurchatov Institute», Moscow, Russia

The FNS-ST spherical tokamak [1] is of particular interest for development as a neutron source, since it can provide higher steady-state neutron flux densities than classical tokamaks [2]. When choosing the device operation parameters, it is assumed that the non-inductive current drive in FNS-ST may be achieved with an energetic neutral beam injection (NBI). The choice of a neutral beam (NB) production scheme is mainly determined by beam energy; neutral beams with energy $E_{\mathrm{b}}>140 \mathrm{keV}$ can be more effective in plasma heating and current drive, while they can be efficiently produced only from negative ions. For small tokamak reactors, positive-ion-based injectors with smaller dimensions seem more attractive, thus the lower energy interval of $100-140 \mathrm{keV}$ is considered too, and the final choice of operating energy will be based on the total NBI efficiency optimization. In the framework of this study, injection efficiency was estimated in terms of current ratio, i.e. the ratio between the beam current output in plasma and the beam source current input. The analysis is done by a simple approach ( $L N B$, light neutral beam), used for the direct estimation of fast ion (FI) current. The LNB technique has much in common with the model presented in [3], but allows for NB energy optimization without recourse to any scaling laws. It leverages the analytical expressions from [4] to calculate FI thermalization and phase space distributions, and obtain FI current profiles. It has proved to be applicable to selecting the injected beam energy — with account of the NB production scheme, and in agreement with the shine-through losses reduction.

Key words: fusion neutron source, spherical tokamak, neutral beam, injector, beam current, shine-through, light model, LNB, FNS.

DOI: $10.21517 / 0202-3822-2021-44-2-100-106$

\section{ГЕНЕРАЦИЯ ТОКА НЕЙТРАЛЬНЫМ ПУЧКОМ В НЕЙТРОННОМ ИСТОЧНИКЕ ТИН-СТ}

\author{
Е.Д. Длугач, А.А. Панасенков, Б.В. Кутеев, Е.А. Филимонова
}

НИЦ «Курчатовский институт», Москва, Россия

Сферический токамак FNS-ST [1] представляет особый интерес для разработки источника нейтронов, поскольку может обеспечить более высокую стационарную плотность потока нейтронов по сравнению с классическими токамаками [2]. При выборе параметров работы установки предполагается возможность неиндуктивной генерации тока в ТИН-СТ пучком быстрых атомов (NBI). Выбор схемы инжекции нейтрального пучка $(\mathrm{NB})$ определяется энергией пучка. Нейтральные пучки энергией $E_{\mathrm{b}}>140$ кэВ более эффективны с точки зрения нагрева и генерации тока, но технология их получения основана на ускорении отрицательных ионов. Что касается компактных токамаков, то инжекторы на положительных ионах, которые имеют более скромные габариты, более привлекательны, поэтому для них также рассматривается более низкий интервал энергии $100-140$ кэВ, и окончательный выбор энергии будет сделан с учётом оптимизации совокупной эффективности инжекции пучка. В данной работе эффективность инжекции оценивается в терминах усиления токов, т.е. в виде отношения между результирующим током пучка в плазме и током, извлекаемым из ионного источника. Анализ выполнен с помощью простой модели пучка ( $L N B$, лучевой нейтральный пучок), который позволяет быстро получать ток быстрых ионов в процессе их торможения в плазме. Указанная модель имеет много общего с моделью [3], но позволяет оптимизировать энергию пучка без использования скейлингов. Модель LNB использует аналитические выражения [4] для расчёта термализации быстрых ионов (FI) и их распределения в фазовом пространстве, а также для получения профилей тока. Указанная методика применена для выбора энергии инжектируемого пучка с учётом эффективности его производства и в пределах допустимой нагрузки от пучка на первой стенке.

Ключевые слова: термоядерный источник нейтронов, сферический токамак, нейтральный пучок, инжектор, генерация тока, сквозные потери, лёгкая лучевая модель, LNB, ТИН-CT.

\section{INTRODUCTION}

Spherical tokamaks (ST) can provide higher neutron flux density and better compatibility with fission blankets than classical tokamaks, and at a much lower cost. However, heating and current drive (CD) systems can increase the entire device cost essentially and should be designed with maximum care.

The FNS-ST [1] tokamak is supposed to provide a high steady-state neutron flux of about $\sim 10^{18} \mathrm{n} / \mathrm{s}$. The machine operation parameters are selected from the assumption that non-inductive current drive is achieved in FNS-ST using energetic atoms injection. Fast neutral beam is the most efficient current source, as the generated fast ions directly produce the current parallel to the magnetic field. The beam driven current together with bootstrap current can fully replace the inductive current in plasma, making steady-state operation possible.

In a nominal operation mode, nuclear fusion reactions from high-energy ions slowing down in plasma should contribute up to $90 \%$ to overall neutron generation. In other words, FNS-ST neutrons are expected to 
originate mainly from $\mathrm{D}-\mathrm{T}$-fusion reactions between hot injected beam particles (or high-energy tails) and core plasma ions that form the Maxwell background [2]. An example of NB optimization for FNS-ST steady-state operation is given in [3], where a system (zero-dimensional) approach is proposed for scanning the machine parameters; and ITER scaling laws are used to assess CD and plasma heating. Fusion power gain ( $\left.Q_{\text {fus }}\right)$ proved to be highly sensitive to deuterium beam energy, due to the beam-plasma interaction. It reaches a $\sim 0.8$ peak at $E_{\mathrm{b}}=300 \mathrm{keV}$, and falls down to $\sim 0.5$ at $E_{\mathrm{b}}=100-150 \mathrm{keV}$. Because the production of neutral beams with $E_{\mathrm{b}}>140 \mathrm{keV}$ from positive ions is ineffective, the decreased energy range is considered as well [3]. Finally, the interval of injected deuterium beam energy optimization is $E_{\mathrm{b}}=100-300 \mathrm{keV}$.

The best CD efficiency is typically achieved at higher electron temperatures and lowest plasma density in order to maximize the fast ion slowing down time, and by choosing the beam energy is close to the so-called critical energy [4]. All beam-driven effects including current generation, beam-plasma fusion, plasma heating and rotation, are very sensitive to the initial deposition of fast ions (FI), the latter being mainly defined by the beam penetration path in plasma. In short, the beam penetration depth, fast ion current amplification in plasma, and shine-through losses are the principal figures of merit when choosing the operation gap for beam-plasma system.

The spatial and angular structure of the injected beam can smear the beam deposition shape, which normally results in the beam capture and CD decrease as compared to pencil beam models. In compact tokamak systems the beam width is comparable with the plasma core radius, and the beam geometry is even more critical as the combination of distorted FI distributions across magnetic surfaces with wider pitch-angle and ions energy profiles essentially reduce the expected beam current gain and neutron output. A way to measure these 3D effects is to use a beam-plasma model that would account for the entire geometry of a given beam-plasma system, including the source beam detailed specification and plasma magnetic configuration.

The NBI total efficiency can be estimated in the terms of Current ratio, i.e. the beam output in plasma (or current circulating around the torus) referred to the beam source input, in current, so that the total NBCD efficiency is calculated as a product of the injector yield in neutralized current, the beamline transmission coefficient, and the beam current amplification in plasma. The beamline transmission is beyond the scope of this paper and is assumed to be constant regardless of beam energy. The focus of this paper is more on the enhancement of neutral beam injection performance and beam energy optimization with a view to maximizing plasma current output.

A simple technique (LNB, light neutral beam) is proposed for the beam current direct and fast estimation; it has much in common with the model presented in [3], but enables the calculation of beam-driven quantities without recourse to ITER scaling laws for NBCD (the reliance on those laws may not deliver accurate results in the case of compact devices). The LNB method is also useful in the sensitivity analysis of beam deposition in plasma, as it allows a comprehensive evaluation of beam geometry and spectra effects on CD (however, this is outside the scope of this paper). The LNB technique is based on the analytical expressions for neutral beam heating [4], and allows calculation of beam ion thermalization and current, spatial distributions and energy profiles directly by the beam bunch tracing through 3D plasma. The technique is applied to evaluate the compound beam current from all the injected beam fractions (energy groups), and to select optimum operation range with account of the NB production scheme.

Due to FNS-ST device rather small size, the beam capture in plasma should be not less than $95 \%$ within the range of plasma density considered. Therefore, prior to optimizing the injection geometry, we lowered the upper value of the injected beam energy to ensure that the beam capture efficiency is high enough for the designed range of plasma densities and that the lost beam fraction (shine-through) does not damage the plasma facing surfaces.

\section{NBI SCHEME FOR FNS-ST}

The NBI system for FNS-ST will include 3 or 4 injectors, each delivering 3.5 MW power to FNS-ST plasma (deuterium + tritium), so that the total steady-state beam power injection is $10 \mathrm{MW}$ (in deuterium). The beam port size is $0.3 \times 0.6 \mathrm{~m}$. The injection axis is horizontal $(\mathrm{Z}=0)$, the positions of tangential injection points are variable: $R=0.4-0.6 \mathrm{~m}$. The system's main parameters are summarized below:

Aspect ratio $R / a, \mathrm{~m}$...

Elliptic elongation $k \ldots$

Toroidal magnetic field, $\mathrm{T} \ldots$

Electron temperature $T_{e}, \mathrm{keV} \ldots$
$0.5 / 0.3$

$\sim 3(2.75)$

1.5

$1-5$ 


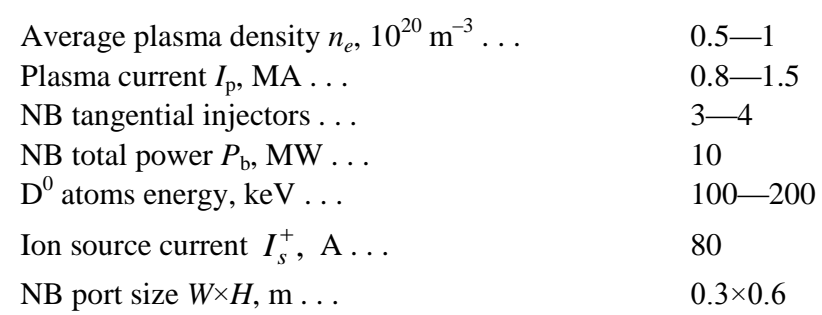

The choice of the beamline design for the NB injection is based on the following considerations. There are two possible design solutions, one based on a positive ion source (PIS), the other on a negative ion source (NIS). A PIS-based injector neutral output in current decreases rapidly with increasing NB energy in the range of $100-300 \mathrm{keV}$, thus it is not so efficient to generate NB at $E_{\mathrm{b}}>140 \mathrm{keV}$ needed to reach the plasma core. A negative-ion-based NBI scheme offers the prospect of much higher neutral fractions for high-beam energy, with the neutral output remaining almost constant and close to $\sim 60 \%$. Also, a NIS-based injector enables a better beam transmission, with beam divergence being twice as small as that observed with the PIS beam technology. On the other hand, the PIS-based NBI provides higher (by at least an order of magnitude) densities of extracted ion current and features a more compact beamline setup. In addition, the positive-ion technology has been extensively studied and used.

A detailed performance analysis and comparison of the two NB production schemes have been performed, and the following conclusions have been made:

- the choice of the NBI scheme depends on the energy of injected atoms: for $E_{\mathrm{b}}>140 \mathrm{keV}$, the NIS is preferable. For lower energy, a detailed analysis of beamline efficiency will tell;

- whatever the NBI design, the NBI vacuum vessel (VV) should be mounted horizontally. The VV, together with the beamline components, is more than 100 MT in weight; its fastening and alignment, as well as remote maintenance are difficult if the platform is inclined;

- the NIS-based injector has the advantages of a highly efficient atom production, regardless of atom energy, beam higher transmission to plasma, and a more compact electrostatic residual ion dump (ERID);

- the drawbacks of the negative-ion technology include lower $\mathrm{D}^{-}$current density $\left(\sim 20 \mathrm{~mA} / \mathrm{cm}^{2}\right)$ at the source exit, the neutral beam halo fraction (15\% of beam particles), which decreases NBI performance and raises power loads, plasma emitter non-uniformity across large emissive surface leading to higher beam divergence;

- the advantages of a PIS-based injector (for $E_{\mathrm{b}}<140 \mathrm{keV}$ ) are: high D current density $\left(200 \mathrm{~mA} / \mathrm{cm}^{2}\right.$ ) at the source exit (i.e. lower emitter area), smaller neutralizer dimensions, reduced gas flow (target thickness), the neutralizer can be attached to the ion source (reduced gas load for cryopanels, as compared with NIS);

- the drawbacks of the PIS-based NBI include: a 2-fold lower power efficiency, molecular ion fractions in the source $-\mathrm{D}_{2}^{+}(15-20 \%)$ and $\mathrm{D}_{3}^{+}(10 \%)$ which produce due to dissociation and neutralization the lowerenergy atoms $(E / 2$ and $E / 3)$, the latter are ionized and captured by plasma periphery reducing resultant $\mathrm{NBCD}$; compact electrostatic RID deflection and dumping system cannot be used (due to the high current density and volume charge), instead, magnetic deflection is employed, with dumping surfaces fitting all energy fractions; for $E_{\mathrm{b}} \sim 140 \mathrm{keV}$, the residual power in ions can be twice as high as the neutral power, hence the magnetic RID becomes the most power loaded component of the injector.

Given the small size and relatively wide plasma density range in FNS-ST, the beam energy interval was checked to meet the $>95 \%$ capture criterion to prevent the shine-through damage of the camera first wall. According to preliminary shine-through estimations, a deuterium beam with $E_{\mathrm{b}} \sim 200 \mathrm{keV}$ can produce $\sim 5 \mathrm{MW} / \mathrm{m}^{2}$ peak power density at the first wall, for mean plasma density $1 \times 10^{20} \mathrm{~m}^{-3}$. Thus, the operation with $200 \mathrm{keV}$ beams will only be possible at a plasma density exceeding $1.5 \times 10^{20} \mathrm{~m}^{-3}$, and $E_{\mathrm{b}} \sim 300 \mathrm{keV}$ beams - from $2 \times 10^{20} \mathrm{~m}^{-3}$. Plasma operation at lower densities will only be safe with the NB energy below $E_{\mathrm{b}} \sim 150 \mathrm{keV}$ and provide the expected shine-through of $<2 \mathrm{MW} / \mathrm{m}^{2}$.

With all these considerations in mind it was finally decided to use the PIS based scheme with deuterium beam energy $100-140 \mathrm{keV}$, and with $\sim 3.5 \mathrm{MW}$ power injected by each NB module. In this scheme, beam content $\left(\mathrm{D}^{+}\right.$and $\left.\mathrm{D}^{0}\right)$ in a thick gas target is defined by the ratio of cross-sections of two competing processes - charge exchange and ionization, and achieves equilibrium when the gas target is infinitely thick. This ratio (as well as the maximum atomic yield, $F^{0}$ ) is a function of the beam energy, $E_{\mathrm{b}}$, and the equilibrium neutral fraction decreases rapidly with increasing 
energy, as shown in Fig. 1. To provide an infinitely thick target, for which equilibrium is attainable, one needs a very long neutralizer and extremely large gas flow. Therefore, in a PIS-based injector, a nominal gas thickness point is chosen for $95 \%$ of the maximum atomic yield. The optimum target thickness $\left(F_{95}=0.95 F^{0}\right)$ in a PIS-based NBI rises almost linearly with the beam energy. Power contained in the residual charged part of the beam after neutralization is comparable with the neutral power injected to plasma. For $E_{\mathrm{b}} \sim 140 \mathrm{keV}$, the dumped residual power can be twice as high as the neutral beam power, making RID the most loaded NBI component.

The ion beam extracted from a positive ion source contains three particle species: $\mathrm{D}^{+}, \mathrm{D}_{2}^{+}(15-20 \%)$, and $\mathrm{D}_{3}^{+}(\sim 10 \%)$. Molecular ions, while passing

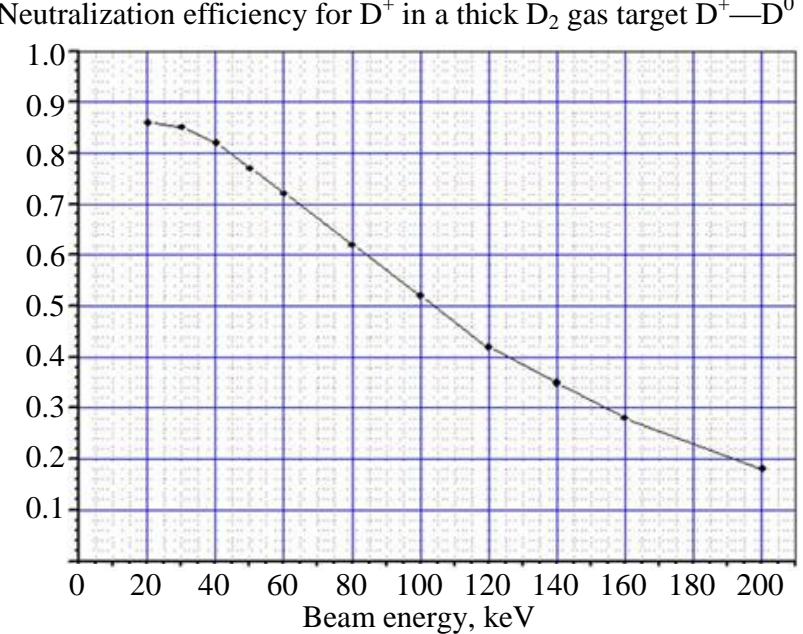

Fig. 1. Energy dependence of the equilibrium neutral fraction in a deuterium beam

through a gas cell, dissociate and after neutralization produce atoms with lower energies $E_{1 / 2}$ and $E_{1 / 3}$. The lowerenergy beam fractions are ionized and captured at the plasma periphery; hence CD calculations should account for the injected beam spectral content.

The neutral beam content was calculated for the 100-140 keV range of injected beam energies - taking into account the source beam species percentage and the neutral yield for each source species $\left(F_{95}\right)$. The results

$\mathrm{T}$ a b l e 1 . Neutral beam fractions $(F)$ and effective neutral yield in current for $I_{s}^{+}=1 \mathrm{~A}$

\begin{tabular}{|c|c|c|c|c|c|c|}
\hline \multirow{3}{*}{ Parameter } & \multicolumn{6}{|c|}{$E_{\mathrm{b}}, \mathrm{keV}$} \\
\hline & \multicolumn{2}{|c|}{100} & \multicolumn{2}{|c|}{120} & \multicolumn{2}{|c|}{140} \\
\hline & $I_{\mathrm{n}}, \mathrm{A}$ & $F\left(I_{\mathrm{s}}^{+}\right)$ & $I_{n}, \mathrm{~A}$ & $F\left(I_{\mathrm{s}}^{+}\right)$ & $I_{n}, \mathrm{~A}$ & $F\left(I_{\mathrm{s}}^{+}\right)$ \\
\hline$\overline{E_{\text {full }}}$ & 0.49 & 0.37 & 0.40 & 0.30 & 0.33 & 0.25 \\
\hline$E_{1 / 2}$ & 1.46 & 0.22 & 1.37 & 0.21 & 1.27 & 0.19 \\
\hline$E_{1 / 3}$ & 2.39 & 0.24 & 2.34 & 0.24 & 2.25 & 0.23 \\
\hline Injected NB current $\mathrm{D}_{1}^{0} I_{\mathrm{b}}, \mathrm{A}$ & \multirow{2}{*}{\multicolumn{2}{|c|}{0.83}} & \multirow{2}{*}{\multicolumn{2}{|c|}{0.74}} & & 0.67 \\
\hline Effective neutral yield $I_{\mathrm{b}} / I_{\mathrm{s}}^{+}$ & & & & & \multicolumn{2}{|c|}{0.67} \\
\hline
\end{tabular}

Comments to Table 1: Atoms $\mathrm{D}_{1}^{0}$ current, [A] - after 95\% neutralization with molecular ions dissociation; $I_{n}$, A - neutralized $\mathrm{D}_{1}^{0}$ output, normalized to $1 \mathrm{~A}$ of each beam fraction; $F\left(I_{\mathrm{s}}^{+}\right), A-$ specific contribution to the neutralized current, for $1 \mathrm{~A}$ of the total ion source current; the source beam content is: $\mathrm{D}^{+}: \mathrm{D}_{2}^{+}: \mathrm{D}_{3}^{+}=0.75: 0.15: 0.10$.

are shown in Table 1 . The source beam fractions ratio $\mathrm{D}^{+}: \mathrm{D}_{2}^{+}: \mathrm{D}_{3}^{+}=0.75: 0.15: 0.10$ in all cases. All the values are normalized to the source beam current (either specific or total) $I_{\mathrm{s}}^{+}=1 \mathrm{~A}$. The injected beam energy corresponds to the basic (full) energy fraction: $E_{\mathrm{b}}=E_{\text {full }}$.

The results of Table 1 are illustrated as a chart in Fig. 2. Based on the neutral yield values, the NB energy $100 \mathrm{keV}$ looks the most attractive for the beamline design.

\section{LNB MODEL FOR BEAM PENETRATION AND IONIZATION}

The NB total efficiency can be defined as a product of total neutralized yield in current, beamline transmission, and fast ion current multiplication in plasma. Although a lower energy beam seems to be more efficient from the NBI perspective, current produced by the beam in plasma can be of higher priority. As a neutral beam produced with PIS technology has three energy fractions, all of them contribute to the beam penetration, ionization and slowdown, pro-

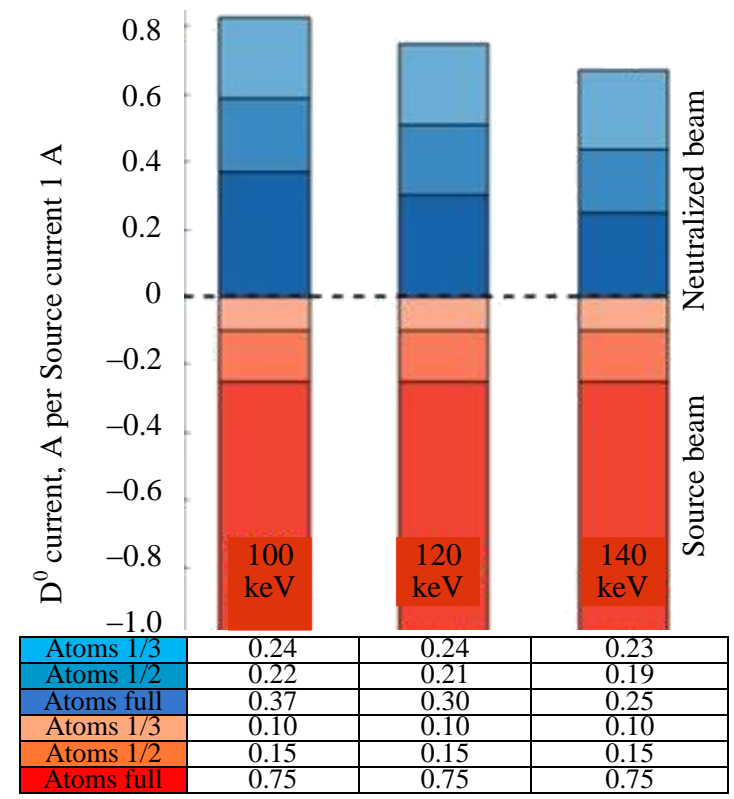

Fig. 2. The neutral beam output fractions $E_{\text {full }}, E_{1 / 2}, E_{1 / 3}$ (blues) for NB energy of 100,120 , and $140 \mathrm{keV}$, respectively. The source beam contents $\left(\mathrm{D}^{+}: \mathrm{D}_{2}^{+}: \mathrm{D}_{3}^{+}\right)$are shown in red colors 
ducing their own fast ion current fraction in plasma. Current drive calculations take into account the actual NB content measured in Fig. 2.

The injected atoms produce a current of fast ions (FI) circulating around the torus. The FI current stacks up during the injection period, and a steady state is reached when the build-up rate of current due to stacking is balanced by the loss rate due to slowing down through collisions with plasma electrons and bulk ions, or to charge exchange of the fast ions with neutral atoms [4].

To calculate beam deposition and CD directly, a simple LNB model (light neutral beam) is used. From the LNB's viewpoint, the beam consists of a large number of rays (or test atoms), whose input structure is predefined (calculated by specialized NBI codes). The direct tracing procedure for each beam ray is discrete and deterministic; it applies analytical expressions [4] and allows beam-driven quantities calculation without recourse to scaling laws (which may be not quite applicable to small devices). Although LNB accepts the detailed beam configuration and spectra effects, these are beyond the scope of this paper. The results shown are obtained for a thin beam (single ray) direct tracing in a plasma toroidal target with elliptical cross-section of FNS-ST plasma.

The NB penetration and ionization are calculated using analytical fits of cross-sections proposed by Janev [5]; the procedure scheme and the resulting plot for $E_{\mathrm{b}}=120 \mathrm{keV}$ are shown in Fig. 3. The three energy fractions of the beam are marked in the plot, making clear the significant difference in ionization rates between the fractions. The crosssection for the lower-energy beam fraction $\left(E_{1 / 3}\right)$ is almost 3 times higher than that for the $E_{\text {full }}$ beam fraction.
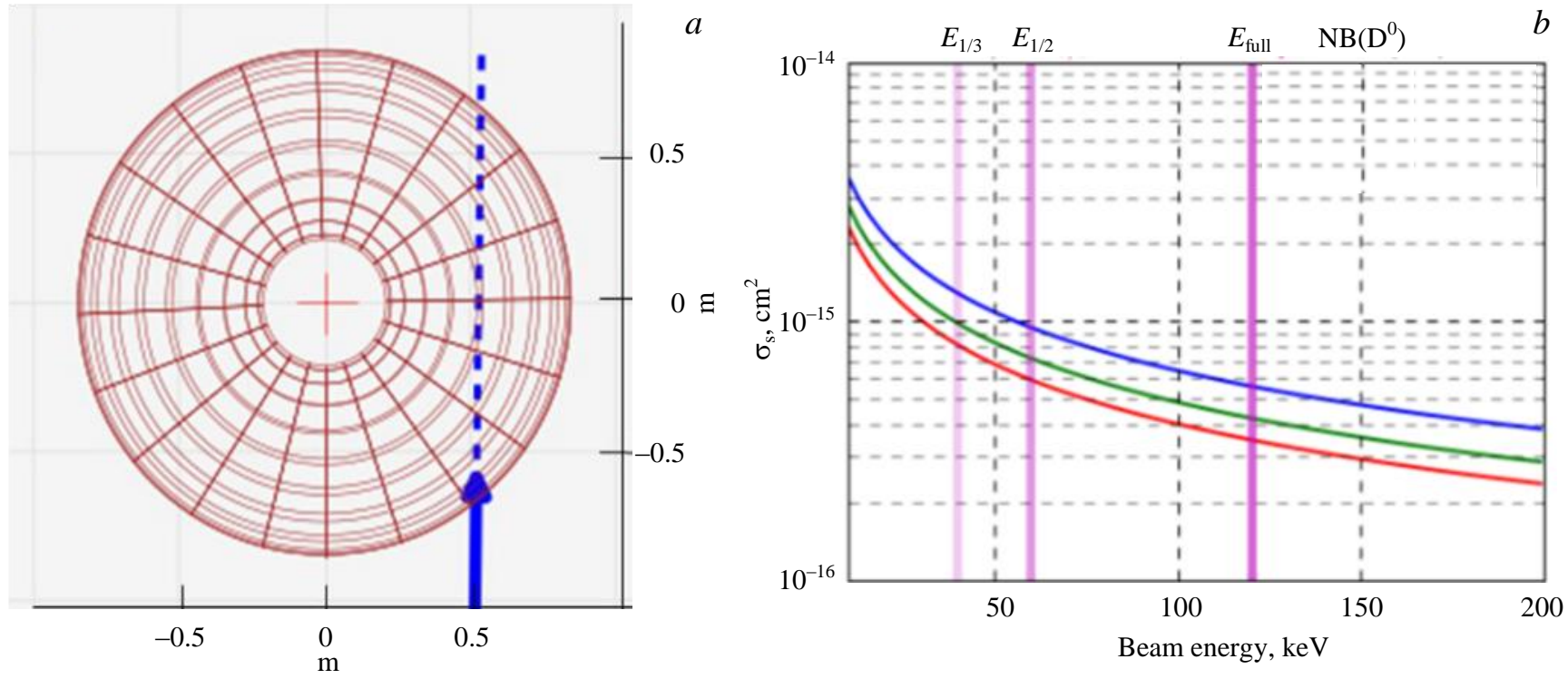

Fig. 3. The LNB scheme of single ray injection to FNS-ST $(a)$, and energy dependence of beam-stopping cross-sections $(b)$ calculated for D-beam $E_{\text {full }}=120 \mathrm{keV}$ for plasma temperature $T_{e}=1 \mathrm{keV}$ and for plasma densities $n_{e}=0.1 \times 10^{20} \mathrm{~m}^{-3}(-), 1 \times 10^{20} \mathrm{~m}^{-3}(-)$, $10 \times 10^{20} \mathrm{~m}^{-3}(\longrightarrow)$

\section{FAST IONS SLOWING-DOWN AND CURRENT GENERATION}

The NBI fast ions distribution in phase space can be calculated by solving the kinetic equation with a beam produced source term and the collision operator, which includes fast ion slowing-down and pitch angle scattering. As opposed to the Fokker-Planck equation numerical solution for reduced phase space, LNB directly calculates the NB slowing down path in plasma toroidal geometry - from the instant the FI source distribution generated along each beam ray. The fast ion toroidal current is supposed to be produced by the ions velocity component parallel to the magnetic field. The plasma is assumed to be steady-state and unaffected by the beam. The charge-exchange FI losses are ignored, as are the electron screening of FI current, radial diffusion, and orbit effects. The net CD value is calculated as: $I_{\mathrm{NB}} \mathrm{CD}=I_{\mathrm{FI}}$. Due to these approximations, LNB model allows the evaluation of the beam-driven quantities upper bounds, with the geometry optimization.

The characteristic time for the beam ions slowing down to the thermal energy including the drag force on plasma ions and electrons, is taken from [4] as: $\tau_{s}=\frac{\tau_{\mathrm{se}}}{3} \ln \left[1+\left(\frac{E_{\mathrm{b}}}{E_{\mathrm{c}}}\right)^{3 / 2}\right]$. Here $\tau_{\mathrm{se}} \propto\left(T_{e}^{3 / 2} / n_{e}\right)$ is the Spitzer ionelectron slowing-down time, see 5.4.3 in [4], $\propto$ - means «proportional», and $E_{\mathrm{c}}=14.8\left(A_{\mathrm{b}} / A_{i}^{2 / 3}\right) T_{e}$ - the critical energy. The critical energy for a D-beam in a D-plasma at $T_{e}=5 \mathrm{keV}$ is $\sim 93 \mathrm{keV}\left(\sim 19 T_{e}\right)$. 
The FI toroidal current from the NB, normalized by $1 \mathrm{~A}$ injected is shown in Fig. 4 as a function of NB energy. The plot is calculated for mono-energetic deuterium beam (LNB) injected to FNS-ST plasma with $T_{e}=5 \mathrm{keV}, n_{e}=1 \cdot 10^{20} \mathrm{~m}^{-3}$. The beam is injected in equatorial plane, the target radius is $R_{\mathrm{t}}=0.5 \mathrm{~m}$. The plasma kinetic profiles $\left(T_{e}, n_{e}\right)$ are assumed parabolic with maximum at the magnetic axis.

Clearly, the energy dependence of the beam current is quite strong - 2-time energy rise results in threefold increase of NB current. It means that the total NB ratio can be more affected by the FI efficiency, than by neutralization yield in the injector.

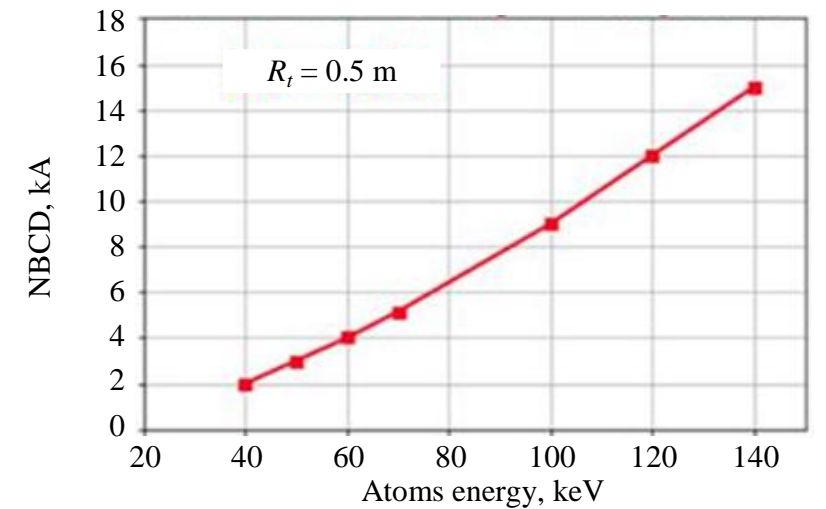

Fig. 4. LNB normalized toroidal current in FNS-ST due to fast ions slowing-down within the energy range selected for PIS-scheme

\section{NBI TOTAL EFFICIENCY IN CURRENT}

As the injected beam in PIS scheme comes with three energy fractions $\left(E_{\text {full }}, E_{1 / 2}\right.$ and $\left.E_{1 / 3}\right)$, the cumulative ionization and current drive are calculated with the weight of each fraction. The calculations are made for the following values of NB energy: $E_{\mathrm{b}}=E_{\text {full }}=100,120,140 \mathrm{keV}$. The neutral beam content is taken from Table 1, calculated for the source beam ratio $D^{+}: D_{2}^{+}: D_{3}^{+}=0.75: 0.15: 0.10$. The results of the specific FI current fractions and total FI current per 1 A injected are shown in Table 2. All the values are normalized to the injected current (specific or total) $I_{\mathrm{b}}=1 \mathrm{~A}$. The last row of the table shows the total NB efficiency in current $\left(I_{\mathrm{CDtol}} I_{\mathrm{s}}^{+}\right)$, represented as a product $F\left(I_{\mathrm{s}}^{+}\right) \times G\left(I_{\mathrm{b}}\right)$.

$\mathrm{T}$ a b l e 2. Fast ions current (kA), efficiency, and total FI current in plasma for $I_{\mathbf{b}}=1 \mathrm{~A}$

\begin{tabular}{|c|c|c|c|c|c|c|}
\hline \multirow{3}{*}{ Parameter } & \multicolumn{6}{|c|}{$E_{\mathrm{b}}, \mathrm{keV}$} \\
\hline & \multicolumn{2}{|c|}{100} & \multicolumn{2}{|c|}{120} & \multicolumn{2}{|c|}{140} \\
\hline & $I_{\mathrm{CD}}, \mathrm{kA}$ & $G\left(I_{\mathrm{b}}\right)$ & $I_{\mathrm{CD}}, \mathrm{kA}$ & $G\left(I_{\mathrm{b}}\right)$ & $I_{\mathrm{CD}}, \mathrm{kA}$ & $G\left(I_{\mathrm{b}}\right)$ \\
\hline$\overline{E_{\text {full }}}$ & 9 & 4.05 & 12 & 4.87 & 15 & 5.61 \\
\hline$E_{1 / 2}$ & 3 & 0.8 & 4 & 1.13 & 5.2 & 1.47 \\
\hline$E_{1 / 3}$ & 1.7 & 0.5 & 2 & 0.66 & 2.5 & 0.87 \\
\hline $\mathrm{NBCD} I_{\mathrm{CD} \text { tot }}, \mathrm{kA}$ & & 5.35 & & 6.66 & & 7.95 \\
\hline Effective $\mathrm{NB}$ ratio $I_{\mathrm{CD} \text { tot }} / I_{\mathrm{S}}^{+}$ & \multicolumn{2}{|c|}{4.43} & \multicolumn{2}{|c|}{4.93} & \multicolumn{2}{|c|}{5.34} \\
\hline
\end{tabular}

Comments to Table 2: $I_{\mathrm{CD}}, \mathrm{kA}-\mathrm{FI}$ current, normalized to 1 A injected in a beam fraction; $G\left(I_{\mathrm{b}}\right)$, kA - specific fraction contribution to the FI current, for $1 \mathrm{~A}$ current injected.

Data from Table 2 are presented as a chart in Fig. 5. It can be seen that for the energy range selected, the neutralization yield is the highest at $E_{\mathrm{b}}=100 \mathrm{keV}$, but the overall NBI efficiency is the best at the upper limit $E_{\mathrm{b}}=140 \mathrm{keV}$, so that the current gain $I_{\mathrm{CDtot}} / I_{\mathrm{s}}^{+}$ hits the maximum and can be about $5.34 \mathrm{kA}$ per $1 \mathrm{~A}$ delivered by the ion source. For example, the NB source current $80 \mathrm{~A}$ would produce the output FI current: $I_{\mathrm{CD} \text { tot }}=354 \mathrm{kA}-$ for $E_{\mathrm{b}}=100 \mathrm{keV}$ (the ion beam source power is $\left.P_{0}=8 \mathrm{MW}\right) ; I_{\mathrm{CD} \text { tot }}=430 \mathrm{kA}$ for $E_{\mathrm{b}}=140 \mathrm{keV}$ (and $P_{0}=11.2 \mathrm{MW}$ ).

\section{CONCLUSION}

NBI shows the best current generation performance among various plasma heating and $C D$ systems. NBI is particularly important for fusion neutron sources design, as it makes the largest contribution to neutron production. In FNS-ST tokamak the beam-

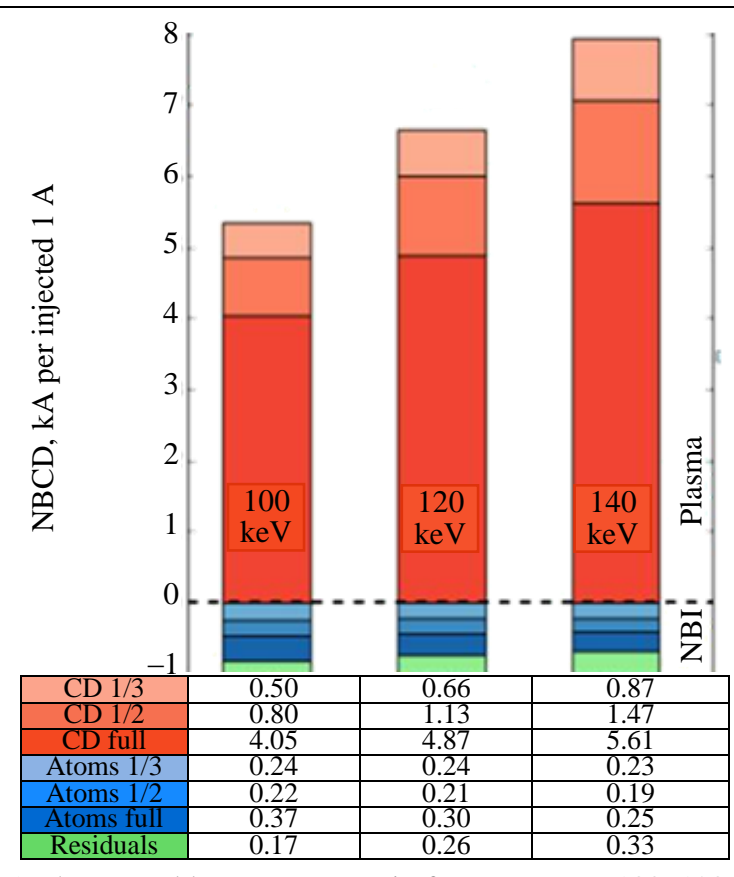

Fig. 5. The neutral beam current gain for NB energy 100, 120, and $140 \mathrm{keV}$ (red colors). The neutral beam fractions $\left(E_{\text {full }}, E_{1 / 2}, E_{1 / 3}\right)$ are shown in blues, the residual ions fraction - in greens 
plasma fusion is expected to be the main source of neutrons, so the neutral beam should be effectively captured by plasma and produce the high-energy tails in the ions spectra needed for beam-plasma fusion and neutron generation. As the fusion rates in the two-component system (beam + plasma) highly depend on the fast ions current and energy distributions, NBI shall be optimized to provide a reliable mechanism of steady-state current drive and fusion rate control.

The NB efficiency in current grows with the beam energy due to the beam higher penetration to the plasma core and longer ion relaxation time. However, the shine-through fraction increases with the beam energy as well, and both effects are measured when deciding on a particular energy value. The radial profiles of beam current generation strongly depend on the beam 3D deposition in plasma, the latter being sensitive to the beam structure, beam energy, the injection geometry (tangent point and tilting), plasma density and temperature profiles. All these effects have to be accounted for in the NBI optimization based on the beam efficiency study.

Initial assessment of beam deposition and slowing-down with LNB technique has proved, that for the energy range of $100-140 \mathrm{keV}$, a neutral beam with a nominal energy of $\sim 140 \mathrm{keV}$ is the best performer in terms of current drive. Although the neutral beam of $140 \mathrm{keV}$ is produced with lower efficiency in current (67\%), the current gain in plasma referred to the beam source current is the best (with multiplication factor $~ 8000$ ), due to the longest path of the hot ions thermalization. For a beam source current of $80 \mathrm{~A}$ it provides a $\sim 430 \mathrm{kA}$ current of fast ions driven by the beam.

The work is supported by NRC «Kurchatov Institute».

\section{REFERENCES}

1. Kuteev B.V. et al. Steady state operation in compact tokamaks with copper coils. - Nucl. Fusion, 2011, vol. 51, p. 073013.

2. Goncharov P.R., Kuteev B.V., Golikov A.A., Lukash V.E., Khayrutdinov R.R., Shpansky Yu.S., Sergeev V.Yu., Bykov A.S., Gryaznevich M.P. Comparison between neutron yields of classical and spherical tokamaks. - VANT. Ser. Termoyadernyi sintez (Problems of Atomic Science and Technology. Ser. Thermonuclear Fusion), 2011, issue 2, p. 36 - 43 (in Russian).

3. Golikov A.A., Kuteev B.V. Choice of parameters for steady state operation in a compact toкамак. - VANT. Ser. Termoyadernyi sintez (Problems of Atomic Science and Technology. Ser. Thermonuclear Fusion), 2010, issue 2, p. 50 - 58 (in Russian).

4. Wesson J. Tokamaks, 4th Edition 2011, Oxford: Oxford University Press.

5. Janev R.K. et al. Penetration of energetic neutral beams into fusion plasmas. — Nucl. Fusion, 1989, vol. 29, p. 2125.

\section{AUTHORS}

Eugenia D. Dlougach, senior scientist, NRC «Kurchatov Institute», 1, Academika Kurchatova sq., Moscow, 123182, Russia, edlougach@gmail.com

Alexander A. Panasenkov, PhD Head scientist, NRC «Kurchatov Institute», 1, Academika Kurchatova sq., Moscow, 123182, Russia, Panasenkov_AA@nrcki.ru

Boris V. Kuteev, Professor, Deputy Head Tokamak Department Fusion Research Centre; NRC «Kurchatov Institute», 1, Academika Kurchatova sq., Moscow, 123182, Russia, Kuteev_BV@nrcki.ru

Elena A. Filimonova, scientist, VANT assistant editor; NRC «Kurchatov Institute», 1, Academika Kurchatova sq., Moscow, 123182, Russia, alb@fc.iterru.ru 